\title{
Long term ocean simulations in FESOM: Evaluation and application in studying the impact of Greenland Ice Sheet melting
}

Xuezhu Wang, Qiang Wang, Dmitry Sidorenko, Sergey Danilov, Jens Schröter, Thomas Jung

Alfred Wegener Institute for Polar and Marine Research, Bremerhaven, 27568, Germany

+49-471-4831-1855

+49-471-4831-1797

Xuezhu.Wang@awi.de

Abstract

The Finite Element Sea-ice Ocean Model (FESOM) is formulated on unstructured meshes and offers geometrical flexibility which is difficult to achieve on traditional structured grids. In this work the performance of FESOM in the North Atlantic and Arctic Ocean on large time scales is evaluated in a hindcast experiment. A water-hosing experiment is also conducted to study the model sensitivity to increased freshwater input from Greenland Ice Sheet (GrIS) melting in a $0.1 \mathrm{~Sv}$ discharge rate scenario. The variability of the Atlantic Meridional Overturning Circulation (AMOC) in the hindcast experiment can be explained by the variability of the thermohaline forcing over deep convection sites. The model also reproduces realistic freshwater content variability and sea ice extent in the Arctic Ocean. The anomalous freshwater in the water-hosing experiment leads to significant changes in the ocean circulation and local dynamical sea level (DSL). The most pronounced DSL rise is in the northwest North Atlantic as shown in previous studies, and also in the Arctic Ocean. The released GrIS freshwater mainly remains in the North Atlantic, Arctic Ocean and the west South Atlantic after 120 model years. The pattern of ocean freshening is similar to that of the GrIS water distribution, but changes in ocean circulation also contribute to the ocean salinity change. The changes in Arctic and sub-Arctic sea level modify exchanges between the Arctic Ocean and subpolar seas, and hence the role of the Arctic Ocean in the global climate. Not only the strength of the AMOC, but also the strength of its decadal variability is notably reduced by the anomalous 
freshwater input. Comparison to previous studies shows that FESOM can well simulate the past ocean state and the impact of increased GrIS melting under the climate change.

Keywords: Unstructured mesh ocean modeling, Greenland ice sheet, Sea level, Atlantic Meridional Overturning Circulation, Arctic Ocean change 


\section{Introduction}

Models formulated on unstructured meshes offer geometrical flexibility which is difficult to achieve on traditional structured grids. The resolution refinement on unstructured meshes can be considered as an effective nesting algorithm, which is valuable for many practical tasks. The Finite Element Sea-ice Ocean Model (FESOM) was designed with this idea in mind. It uses triangular surface meshes and generalized vertical discretization, and offers necessary parameterization commonly used in large-scale ocean modeling. There are, however, numerous implementation details that differ from structured-mesh models, which may influence the model performance over long integration time. Therefore, a careful examination of model behavior on long time scales is required. This was partly the focus of the intercomparison of FESOM (Sidorenko et al. 2011) to other models participating in the project of Coordinated Ocean-ice Reference Experiments (COREs) under normal year forcing (Griffies et al. 2009). The current paper is a following step in this direction and deals with long-term FESOM simulations under CORE inter-annual forcing with and without freshwater contribution from the Greenland Ice Sheet (GrIS) melting.

The accelerated melting of the GrIS, associated to global warming, may significantly impact the entire climate system and the ocean in particular (Fichefet et al. 2003; Stouffer et al. 2006; Gerdes et al. 2006; Jungclaus et al. 2006; Swingedouw et al. 2006, 2007; Stammer 2008; Stammer et al. 2011; Hu et al. 2009, 2011; Kopp et al. 2011) . The increasing freshwater input can affect the ocean in several ways. First, it leads to the global sea level (GSL) rise due to added mass. The local sea level (LSL) change differs from the GSL change because of contributions linked to ocean dynamics (dynamical sea level (DSL) change due to steric height response and change in circulation) and change in static equilibrium (SE) caused by the gravitational, elastic and rotational effects of mass redistribution. Although the GSL rise can easily be estimated for a given discharge rate from Greenland, LSL change remains a topic of ongoing research. Climate models are required to estimate the DSL response, while glacial rebound modeling is required to assess the SE effects. Second, the added freshwater influences the ocean circulation by stabilizing the water column in the deep 
convection sites, thus suppressing the Atlantic meridional overturning circulation (AMOC) and meridional heat transport. Understanding such effects is crucial for understanding the climate change and requires climate model assisted studies. This is a key topic of many recent climate studies as in the literature mentioned above.

Despite numerous studies of the AMOC response to increased GrIS melting, the predicted response is still a matter of debate. Fichefet et al. (2003) and Swingedouw et al. $(2006,2007)$ found a substantial suppressing effect of GrIS melting on AMOC, while Jungclaus et al. (2006) suggested that the backbone of the AMOC can be maintained in the scenario of warming climate and increased GrIS melting, even though the deep convection is significantly reduced in the Irminger and Labrador Seas. Stouffer et al. (2006) annalyzed a suit of climate model simulations to assess the influence of GrIS freshwater input on the AMOC. All models in their study simulated weakening of the AMOC due to freshwater from GrIS, but the spread of AMOC reduction among these models was approximately $1.5-9 \mathrm{~Sv}$. Thus, a quantitative prediction remains a tough problem at the current stage, and the goal of numerous model studies lies in exploring possible mechanisms through which the added freshwater influences the sea level and meridional overturning circulation. The uncertainties in the simulations can be further increased by the uncertainties in model predictions for future radiative forcing scenarios as addressed in the past IPCC reports. Notwithstanding the spread of model results in aforementioned studies, in our work they provide the possibility to evaluate the FESOM simulation through intercomparison.

Ocean models driven by prescribed atmospheric forcing neglect the feedbacks between the ocean and atmosphere (see, e.g., discussions by Griffies et al., 2009). Another drawback is their use of sea surface salinity (SSS) restoring as the practical remedy for mixed boundary conditions (see, e.g., discussions by Gerdes et al., 2006). However, due to the complexity of coupled climate models and even larger uncertainties in coupled model simulations, hindcast simulations remain the primary way to evaluate ocean models in the ocean modeling community (Griffies et al., 2009). 
In this work we use hindcast experiments with CORE interannual atmospheric forcing (Large and Yeager, 2009) to study FESOM's long term behavior. The freshwater input from the GrIS melting is added in a water-hosing experiment to study the associated ocean response. The focus is on the direct effects of increased freshwater input on the ocean circulation, including the changes in DSL, Atlantic circulation and the Arctic Ocean. Long term model integration using two different scenarios allows to assess the model skills in both reproducing the past ocean state and simulating one particular impact of future climate change. Mash et al. (2010) used an eddy-permitting global ocean model to study the short term (on a few years time-scale) ocean response to sudden GrIS freshwater discharge. For our purpose we used a coarse mesh to study the model long term behavior, as done in most aforementioned studies.

The paper is organized as follows. Section 2 describes the model configuration. The model state without GrIS melt water input is analyzed in section 3. The focus is on the main ocean indices and characteristics in the North Atlantic and Arctic Ocean, which are the two regions mainly discussed when studying the influence of GrIS freshwater in the following section. Section 4 compares the experiments with and without the GrIS freshwater input. Conclusion and discussions are given in the last section.

\section{Model description}

We employ a global version of FESOM, which uses the finite element method and solves the standard set of hydrostatic primitive equations in the Boussinesq approximation (Danilov et al. 2004; Wang et al. 2008; Timmermann et al. 2009). It uses unstructured triangular meshes in the horizontal and tetrahedral elements in the volume. The unstructured meshes have an advantage of providing local refinement in a global setup without traditional nesting. The sea-ice component of FESOM is briefly sketched by Timmermann et al. (2009). It uses the same surface mesh as the ocean component.

We use nominal $1.3^{\circ}$ horizontal resolution in the bulk of the open ocean, and take the advantage of FESOM geometric flexibility to refine the resolution to $20 \mathrm{~km}$ 
along the coastlines and $40 \mathrm{~km}$ in the equatorial belt. This allows us to better resolve the ocean geometry and the equatorial transient processes. As the North Pole is displaced onto the Greenland, the resolution is also about $20 \mathrm{~km}$ in its vicinity. The minimal horizontal resolution of $20 \mathrm{~km}$ still allows us to use a large time step (45 $\mathrm{min}$ ) to carry out long-term integrations. For our current purpose we did not apply further mesh refinement in other particular regions. We use 39 vertical z-levels, with $10 \mathrm{~m}$ thickness in the top 10 layers.

The Redi diffusion (Redi 1982) and the Gent and McWilliams parameterization (Gent and Mcwilliams 1990) are applied with the critical neutral slope of 0.004 . The skew diffusivity is the same as the isopycnal diffusivity, which is parameterized as $\mathrm{V} \Delta$, where $\mathrm{V}=0.006 \mathrm{~ms}^{-1}$, and $\Delta$ is the square root of surface triangle area. The horizontal biharmonic viscosity is $\mathrm{B} \Delta^{3}$, where $\mathrm{B}=0.027 \mathrm{~ms}^{-1}$. Vertical mixing is provided by the Pacanowski and Philander scheme (Pacanowski and Philander 1981) with the background vertical diffusion of $10^{-4}$ $\mathrm{m}^{2} \mathrm{~s}^{-1}$ for momentum and $10^{-5} \mathrm{~m}^{2} \mathrm{~s}^{-1}$ for tracers, and the maximum value is set to $0.01 \mathrm{~m}^{2} \mathrm{~s}^{-1}$. The mixing scheme by Timmermann et al. (2002) is introduced (the diffusivity of $0.01 \mathrm{~m}^{2} \mathrm{~s}^{-1}$ is applied over a depth defined by the Monin-Obukhov length when it is positive) in order to avoid unrealistically shallow mixed layers in summer. The performance of FESOM with a similar configuration forced by the climatology forcing (CORE normal year forcing, Large and Yeager, 2004) has been discussed by Sidorenko et al. (2011).

The ocean is initialized with steady velocity and the annual mean potential temperature and salinity climatology of the World Ocean Atlas by Conkright et al. (2002). The sea ice is initialized with results from previous simulations. The model is forced by the CORE inter-annual forcing from 1948 to 2007 (Large and Yeager 2009). The drag and heat exchange coefficients used in the bulk formula are computed following the suggestion of Large and Yeager (2004). The SSS is relaxed toward the monthly climatology with a piston velocity of $50 \mathrm{~m} / 300$ day. The total surface restoring flux is normalized to zero at every time step.

The model is first spun up for 120 years (two cycles of 1948-2007 forcing) and then integrated further in two setups: One is the control run which just continues 
from the spin-up results, and the other is the water-hosing experiment in which the freshwater forcing due to GrIS melting is added around Greenland. Both of them are integrated for two cycles of 60 years. In the water-hosing experiment, the extra freshwater released from the GrIS is uniformly distributed along the Greenland coast south of $76^{\circ} \mathrm{N}$. The total added freshwater flux is $0.1 \mathrm{~Sv}$, the same as in previous studies by Stouffer et al. (2006), Stammer $(2008,2011)$ and Lorbacher et al. (2012). The melting water is applied from May to October. The freshwater flux used here is larger than in the current climate situation, but it is chosen to represent a possible future climate scenario as done in previous studies.

In the water-hosing experiment a passive tracer is introduced to trace the pathway of freshwater from Greenland as suggested by Gerdes et al. (2006). It is set to zero everywhere at the beginning of the experiment. A virtual salt flux (the product of runoff from GrIS melting and local sea surface salinity) leaving the ocean is applied as the surface boundary condition for the passive tracer equation. It is solved using the same equation as for the active tracers.

\section{Simulated state in the control run}

The model performance in the control run is analyzed in this section with focus on the North Atlantic and the Arctic Ocean. We will focus on these areas in the comparison between the control and the water-hosing runs in section 4 .

\subsection{The North Atlantic}

The AMOC is the major component of the global ocean thermohaline circulation, which plays a crucial role in the climate system. Its transport and structure are important for maintaining a realistic ocean state (Griffies et al. 2009). The time series of the annual mean AMOC index, defined as the maximum of the AMOC streamfunction at $45^{\circ} \mathrm{N}$ beneath the wind driven Ekman layer, is shown in Figure 1a. The first two cycles of integration with repeated CORE interannual forcing (120 years) are the spinup phase needed to reach a quasi-equilibrium state in the upper and intermediate ocean. The mean strength of the simulated AMOC during the last two cycles is about $14 \mathrm{~Sv}$, with the standard deviation of $1.7 \mathrm{~Sv}$. The 
simulated AMOC transport compares well with the estimated mean values based on observations, $13 \pm 2 \mathrm{~Sv}$ at $42^{\circ} \mathrm{N}$ (Lumpkin and Speer 2003) and $16 \pm 2 \mathrm{~Sv}$ at $48^{\circ} \mathrm{N}$ (Lumpkin et al. 2008) . Although it is near the lower bound of the observed range, the model result is comparable to previous model simulations (e.g., Griffies et al. 2009).

The AMOC streamfunction averaged over the last ten years of the control run is shown in Figure 1b. The AMOC system consists of two main overturning cells, an intermediate with southward-flowing North Atlantic Deep Water (NADW) and an abyssal one with Antarctic Bottom Water (AABW), both of which are well captured in our control integration. The intermediate cell spans the whole Atlantic in both hemispheres with the maximum located at about $1000 \mathrm{~m}$, while the abyssal one with a strength of $2-3 \mathrm{~Sv}$ is centered around the $3500 \mathrm{~m}-4000 \mathrm{~m}$ depth.

The NADW, which feeds the intermediate cell of the AMOC, is largely sustained by the deep convection and water-mass ventilation in the Labrador and GIN (Greenland-Iceland-Norwegian) Seas. The analysis by Latif et al. (2006) indicates that the outflow from GIN seas plays a secondary role in determining the AMOC variability during the past decades. The Labrador Sea is a region where intense air-sea interaction occurs and strong convective processes create dense Labrador Sea Water (LSW), the upper constituent of the NADW. The mixed layer depth (MLD) in the Labrador Sea can be used as a simple measure of convection and LSW formation intensity. The decadal variability of the Deep Western Boundary Current (DWBC) transport at $53^{\circ} \mathrm{N}$ in the southwestern Labrador Sea follows that of the Labrador Sea MLD with a lag of 1-2 years, which indicates that the DWBC represents a signal of primarily thermohaline origin (Böning et al. 2006) .

The anomalies of the DWBC transport at $53^{\circ} \mathrm{N}$ and the Labrador Sea MLD during the last control run cycle are plotted in Figure 2a. The DWBC is defined using the criterion that the potential density $\left(\sigma_{\theta}\right)$ is larger than $27.74 \mathrm{~kg} / \mathrm{m}^{3}$. The MLD index is calculated as the March mean MLD averaged over a chosen box $\left(55-53^{\circ} \mathrm{W}\right.$, $56.5-58.5^{\circ} \mathrm{N}$ ) in the Labrador Sea. Here, The MLD is defined as the depth where the buoyancy anomaly becomes greater than $0.0003 \mathrm{~ms}^{-2}$ relative to the surface. The DWBC transport well corresponds to the variability in the convection intensity in the Labrador Sea, with a correlation coefficient of 0.6 for a lag of 1 
year. The stronger southward DWBC transport episodes are apparently associated with deeper Labrador Sea MLD in the mid-70s, mid-80s and most prominently, early 90s, consistent to the finding by Böning et al. (2006).

The DWBC plays an important role in exporting the deeper water masses formed in the subpolar gyre southward to feed on the meridional overturning circulation, as well as in setting the variability of the exported water mass and AMOC (Böning et al. 2006; Palter et al. 2008; Bower et al. 2009; Cunningham et al. 2010). It can well explain the variability of the AMOC further to the south (Eden and Greatbatch 2003; Böning et al. 2006). Figure 2b illustrates the variability of DWBC transport at $53^{\circ} \mathrm{N}$ and the AMOC transport at $45^{\circ} \mathrm{N}$. The former leads the latter with a correlation coefficient of 0.81 for a lag of 1 year. This relationship indicates that the signal of AMOC is linked to the variability of upstream deep water transport, especially on the decadal time scale. The MLD in the Labrador Sea leads the AMOC at $45^{\circ} \mathrm{N}$ by about 2 years in our simulation, as also shown by Eden and Greatbatch (2003).

\subsection{The Arctic Ocean}

The Arctic Ocean stores a large amount of freshwater in both solid (sea ice) and liquid form. The variability in freshwater storage and freshwater exchange through critical gateways influence the global large-scale ocean circulation. Simulating reasonable sea ice coverage pattern and freshwater balance is the prerequisite for an adequate representation of the large scale ocean circulation and global climate.

Figure 3 shows the simulated Arctic mean sea ice concentration in March (a) and September (c), compared with the observed sea ice concentration from NSIDC (Cavalieri 1996, updated yearly). March and September have the maximum and minimum Arctic sea ice extent, respectively. Generally, the model reproduces the realistic sea ice coverage in the Arctic Ocean. In winter, the most part of the Arctic is covered with high concentration sea ice due to the ice formation in cold conditions. The model well represents the ice edge around the Arctic periphery. The pronounced Arctic sea ice retreat in September is also well captured, although 
the sea ice area is slightly overestimated in some marginal seas, including Baffin Bay, Barents and Kara Seas.

The total liquid freshwater content in the Arctic Ocean is diagnosed via $\iint_{A} \int_{H}^{0}\left(S_{r e f}-S\right) / S_{r e f} d z d A$, where $\mathrm{S}$ is salinity, Sref $=34.8$ is the reference salinity, $\mathrm{z}$ is water depth, $\mathrm{H}$ is the ocean depth where $\mathrm{S}$ reaches Sref, and $\mathrm{A}$ is the surface area (over the Arctic region). It increases significantly during the first model cycle, as in the spinup phase of other global models (e.g., Köberle and Gerdes 2007), while it is very similar during the last two model cycles (with very close magnitude and variability, not shown). Figure 4a shows the anomaly of the total Arctic liquid freshwater content for the last model cycle. This time series is qualitatively similar to those of Häkkinen and Proshutinsky (2004), Köberle and Gerdes (2007), and Lique et al. (2009), with maxima in late 1960s, at the beginning and end of 1980s, and end of 1990s, and minima in 1976, 1987 and 1996. The standard deviation of the liquid freshwater content is $2.07 \times 10^{3} \mathrm{~km}^{3}$, about $2 \%$ of the long term mean.

The liquid freshwater content variation is due to both the surface freshwater fluxes (precipitation-evaporation+river runoff and ice melting and freezing) and lateral freshwater exchange through the main gateways. The Arctic Ocean receives freshwater contribution from the Pacific through Bering Strait, and releases freshwater to the North Atlantic through Fram Strait and the Canadian Arctic Archipelago (CAA) channels. The relationship between the total lateral freshwater transport and the derivative of the Arctic Ocean freshwater content is shown in Figure $4 \mathrm{~b}$. The variability of the freshwater content in the Arctic Ocean can be largely explained by that of the total freshwater transport through the gateways. The correlation coefficient between the two terms is 0.79 . As shown in previous model studies (Häkkinen and Proshutinsky, 2004; Köberle and Gerdes, 2007; Lique et al., 2009), the lateral advective flux has a leading role in the freshwater content variability. Fram Strait is the gate not only for fresh water export, but also for the inflow of warm saline water of Atlantic origin. The change in the property of the Fram Strait inflow in the GrIS melting scenario can modify the Arctic freshwater content significantly (see section 4.3). 


\section{The GrIS melting scenario}

\subsection{Global dynamical Sea Level change}

The GSL change directly induced by the added water mass is equilibrated through fast barotropic processes. The global barotropic adjustment just takes several days to redistribute the sea level rise globally over the entire ocean. As argued by Gower (2010) and Lorbacher et al. (2012), the actual addition of freshwater leads to a much larger magnitude in the GLS rise than the local DSL rise at most sites. A melting rate of $0.1 \mathrm{~Sv}$ gives a GSL rise rate of approximately $8.8 \mathrm{~mm} / \mathrm{year}$. However, the DSL response is still important locally on this background. Pronounced DSL rise northeast of the North America has been observed in most water-hosing simulations (Stammer 2008; Hu et al. 2009; Yin et al. 2009; Kopp et al. 2010). Note that the static equilibrium (SE) contribution should be accounted for to get the full sea level rise signal. With a GrIS melting rate of $0.1 \mathrm{~Sv}$, the magnitude of sea level depression due to SE can outweigh the DSL rise in the North Atlantic, even in the region where DSL rise is the largest (Kopp et al., 2010). As the ocean circulation and its representation in FESOM is the main topic of this work, we will only focus on the DSL change here, although assessing the future risk of sea level rise requires taking all contributions into account (Slangen et al., 2012).

The modeled sea surface height is corrected as suggested by Greatbach (1994), Griffies and Greatbatch (2012), since the model uses the Boussinesq approximation. The DSL response to the freshwater input induced by GrIS melting is illustrated in Figure 5. The time evolution of annual mean DSL difference between the water-hosing and control runs is shown (for year 2, 4, 6, 10, 15 and 20). The DSL adjustment is dominated by baroclinic wave and advective processes and is much slower than the barotropic GSL adjustment process. As the GrIS freshwater is added along the Greenland coast south of $76^{\circ} \mathrm{N}$, the immediate DSL change largely occurs near the Greenland coast especially in Baffin Bay and Greenland Sea. In the Baffin Bay, the signals of positive DSL anomaly are mainly confined within the local currents at the 
beginning of the experiment, including the northward West Greenland Current and the southward Baffin Island Current. The signals of DSL anomaly in the Greenland Sea propagate along the boundary and penetrate into the Arctic Ocean. After 4 years, the DSL anomaly spreads into the North Atlantic along the subpolar gyre. Then the signals are carried by the North Atlantic Current and spread poleward. Meanwhile, the DSL anomaly also propagates southward from the Labrador Sea toward the equator, where it continues along the equator in form of equatorial Kelvin waves and then propagates poleward along the eastern coast, carrying the signals to the whole Atlantic basin in both hemispheres in form of Kelvin and Rossby waves.

The 'fingerprints' of the wave propagation become more obvious with time as their amplitude increase. After 10 years the DSL anomaly covers the whole Atlantic basin. The sea level change signal is carried to the Indian basins across the southern tip of Africa and after about 15 years it covers the Indian Ocean. It takes about 20 years for the DSL signal to cover the whole Pacific Ocean. However, the magnitude of the DSL change is much larger in the Atlantic and Arctic Oceans.

As indicated in Figure 5, the propagation pathways of the DSL anomaly, one to the subpolar and Arctic regions and one to the Indian and Pacific basins, are dominated by different processes. Advective processes govern the adjustment of DSL change in subpolar and Arctic regions, while the southward propagation is dominated by Kelvin and Rossby waves. The latter pathway was also discussed in previous studies (e.g., Stammer, 2008). The southward propagation in form of Kelvin and Rossby waves in our experiment is similar to that in the study of Stammer (2008), although it is less visible on the background of stronger advective propagation: the positive DSL anomaly first fills the South Atlantic and then penetrates into Indian Ocean around the Good Hope, and finally reaches the Pacific Ocean. However, there is noticeable difference for the North Atlantic and Arctic regions compared to the work of Stammer (2008), in which the Arctic Ocean was absent. Our study shows that the most significant DSL change occurs in the northern North Atlantic and Arctic Ocean through advection. The impact of GrIS melting on the Arctic Ocean will be further discussed in section 4.3. 
Figure 6 shows the mean DSL change for year 50-60 (left) and 110-120 (right). The magnitude of DSL change continues to increase with time, but its spatial distribution is far from being uniform. The sea level anomaly is obviously the largest in the North Atlantic and the Arctic Ocean. By the end of our experiments, the largest DSL rise is observed in Baffin Bay, Labrador Sea and northeast of the North America. The DSL anomaly northeast of the North America, reaching about $30 \mathrm{~cm}$, is rather significant even compared to the mean GSL rise of about 1 $\mathrm{m}$ (from $0.1 \mathrm{~Sv}$ melting rate for 120 years). This result is consistent to previous studies (Hu et al., 2009; Kopp et al., 2010). Yin et al. (2009) suggested that the DSL rise in west North Atlantic can be linked to the weakening of the AMOC, which we will address in section 4.4.

\subsection{Freshwater distribution and ocean salinity change}

Figure 7 a presents the passive tracer at two depths and its vertically integrated value averaged over the last 10 years. It shows the direct freshening effect of GrIS melt water, because the passive tracer is an indicator of the melt water distribution in the ocean. At the sea surface, a large amount of GrIS water is accumulated in Baffin Bay. A significant amount is also distributed over the northern North Atlantic and the Arctic Ocean. At depth, the northern North Atlantic and Arctic Ocean are still the major residence locations of the GrIS melt water, although it is obviously present in the whole North Atlantic and the western South Atlantic. The pattern of the vertically integrated signal is similar to that from Gerdes et al. (2006), with highest value in the North Atlantic subpolar gyre. The Arctic Ocean receives GrIS melt water at different depth through the North Atlantic current, while the South Atlantic receives melt water through the deep limb of the (weakened but not collapsed) meridional overturning cell.

The salinity anomaly (difference between the water-hosing and control runs) at different depth and its vertically integrated value are shown in Figure $7 \mathrm{~b}$. Significant freshening mainly occurs in the northern North Atlantic and Arctic Ocean, similar to the changes implied by the GrIS water distribution (Figure 7a). However, there is a pronounced difference between the salinity anomaly and the 
passive tracer at intermediate depth in the eastern North Atlantic, where fresher intermediate water is formed. Clearly, this water is not GrIS melt water origin, but due to the ocean circulation adjustment. A very similar result was obtained by Gerdes et al. (2006), who conducted the water-hosing experiment with an intermediate complexity climate model. They showed that the minimum salinity in the western boundary current will increase at the beginning of the simulation as the supply of the relatively fresh LSW is reduced due to suppressed deep convection, while the westward spreading of this freshwater pool can finally lead to a decrease in the salinity at the western boundary. Similar to their result, the salinity anomaly in our North Atlantic is negative by large, including the western boundary region. The vertically integrated salinity anomaly is positive along the coast starting from Gulf of Mexico and Caribbean Sea to the south. This is also similar to the finding of Gerdes et al. (2006), but the anomaly magnitude in our model is much smaller. The salinity anomaly pattern (largely negative) in the South Atlantic is different to their results (largely positive). The difference can be due to different ocean adjustment in the South Atlantic or missing atmospheric feedbacks in our experiment, which need to be explored in future work. The northern North Pacific becomes fresher because less freshwater is transported into the Arctic Ocean in the water-hosing run (see section 4.3).

A zonal band of positive salinity anomaly is present near the Gulf Stream Extension both at the intermediate depth and in the vertically integrated field (Figure $7 b$ ), which can be simply due to the shift of the mean Gulf Stream path. Figure 8 shows the mean kinetic energy at surface averaged over the last 10 model years for both runs. In the water-hosing run, the axis of the Gulf Stream Extension shifts by about 1 degree northward to $44^{\circ} \mathrm{N}$, where we see the zonal salinity anomaly. The reduction of the Gulf Stream kinetic energy in the water-hosing experiment is consistent to the reduction of the AMOC strength (see section 4.4).

\subsection{The Influence on the Arctic Ocean}

The Atlantic Water (AW) enters the Arctic Ocean via both Fram Strait and Barents Sea. The two branches meet near the St. Anna Trough. Surface cooling in the Barents Sea increases the AW density, which helps the AW in the Barents Sea 
branch to penetrate deeper into the Eurasian Basin. Figure 9a shows the vertically integrated passive tracer in the Arctic Ocean. A large amount of GrIS water accumulates in the Arctic basins, while the Eurasian Basin has the largest concentration due to the direct access to the AW inflow. The Arctic boundary currents are steered by the bottom topography, in particular the Lomonosov Ridge separating the Eurasian and Amerasian Basins, therefore a large amount of passive tracer is located in the Eurasian Basin. Accordingly, the largest negative salinity anomaly is also there (Figure $9 \mathrm{~b}$ ). The patterns of salinity change and passive tracer are different in their details due to the ocean dynamical adjustment, as for the case in the North Atlantic (Figure 7). The vertically integrated passive tracer and salinity anomaly for the upper 200m depth are shown in Figure 9c and 9d, respectively, comparing which with Figure $9 \mathrm{a}$ and $9 \mathrm{~b}$ indicates that the salinity anomaly reaches deeper depth. The passive tracer has high concentration in both basins. The salinity anomaly has a similar pattern, but with clearly intensified magnitude in the Eurasian and south Canadian Basins.

Figure 10 compares the vertical structure of the passive tracer and salinity anomaly in a transect from the Franz Josef Land to the Canadian Basin (location marked in Figure 9a with a solid black line). The passive tracer penetrates mainly over the upper 2000m depth, including the surface layers and the AW layer, and the ocean freshening is also mainly within this depth range. The most pronounced difference between the passive tracer and salinity anomaly is in the upper $200 \mathrm{~m}$ depth. As also indicated in Figure 9d, the salinity reduction in the upper central Arctic is much less than in the south Canadian Basin. In the deep AW layer the salinity reduction is slightly less than the freshening indicated by the passive tracer.

Figure 11a shows the DSL change averaged over the last 10 years. In the Arctic Ocean, the most pronounced DSL rise is in the Eurasian Basin and along the shelf regions. Similar to the surface circulation change implied by the sea level gradient, the barotropic streamfunction shows a positive anomaly in the Eurasian Basin and a negative anomaly centered over the Mendeleev Ridge (Figure 11b). A very fresh surface water layer resides above the halocline in the Canadian Basin and the changes in circulation can lead to changes in the distribution of the 
freshwater. The typical clockwise surface circulation brings the freshwater in the Canadian Basin close to the Transpolar Drift current, which then brings part of the fresh water to the Fram Strait. The negative streamfunction anomaly implies more freshwater remains in the south and central Canadian Basin and less discharge to the region over the Mendeleev Ridge (Figure 9d, 10b). The positive barotropic streamfunction anomaly in the Eurasian Basin indicates that the AW inflow is weakened (Figure 11b). The relatively saltier AW meets the freshwater from the Transpolar Drift west of Severnaya Zemlya. The salinity at this point is influenced not only by the AW salinity, also by the strength of the AW inflow. Weaker AW current results in lower salinity at this place, where the most pronounced negative salinity anomaly is observed (Figure 9d, 10b).

The Arctic receives net volume inflow through Barents Sea opening and Bering Strait, and loses net volume through Fram Strait and Davis Strait. The change in sea surface height can also influence the water mass exchange between the Arctic Ocean and the sub-Arctic seas. The sea level difference between the Arctic Ocean and the sub-Arctic seas has significant impact on the transport variability through the Arctic gateways (e.g., Houssais and Herbaut 2011). As the sea level increases significantly in Baffin Bay more than in the Arctic Ocean, the export transport through CAA and Davis Strait is significantly reduced (Table 1). The direction of the currents through CAA can even reverse depending on seasons and years (not shown), which brings the passive tracer into the Arctic Ocean. As shown in Figure 9c, a notable amount of passive tracer enters the Arctic Ocean via CAA and accumulates in the upper Canadian Basin. Reduced freshwater release through the CAA can also contribute to the freshening in the Canadian Basin (Figure 9d), besides the impact of changing circulation inside the Arctic Ocean discussed above. Due to the coarse resolution used in the model, the simulated transport through the Davis Strait in the control run is lower than the canonical value. Considering the role of the along strait sea level gradient in determining the CAA transport (Houssais and Herbaut 2011), we believe that the reduction in the CAA export transport in the water-hosing experiment is a robust feature, although the amplitude of reduction might be even larger if the simulated transport is stronger in the control run. A global simulation with locally refined CAA region shows that the CAA transport can be much better represented (a paper in preparation). 
The increase in sea level in the Arctic Ocean also leads to reduction in both the Barents Sea and Bering Sea inflow (Table 1). The net transport through Fram Strait does not change significantly, but both the inflow and outflow decreases by $0.3 \mathrm{~Sv}$. The reduced AW inflow explains the strong negative salinity anomaly in the Eurasian Basin as discussed above. The reduction in Pacific freshwater inflow explains the freshening of the northern North Pacific (Figure 7b). Although the AW becomes fresher due to added GrIS melt water, thus increasing the total freshwater content in the Arctic Ocean, the increasing rate declines with time due to the weakening of the AW inflow (Figure 12).

\subsection{The impact on AMOC}

The simulated temporal evolution of AMOC index at $45^{\circ} \mathrm{N}$ for both the control run and the water-hosing experiment is shown in Figure 13. The strength of the simulated AMOC in the GrIS melting scenario drops significantly in comparison with the control run. The mean AMOC index in the last cycle is about $10 \mathrm{~Sv}$ in the water-hosing run, $4 \mathrm{~Sv}$ lower than in the control run. Correspondingly, the Gulf Stream becomes weaker (Figure 8) and a local DSL rise is formed northeast the North America (Figure 6). Previous water-hosing experiments using the $0.1 \mathrm{~Sv}$ melting scenario with coupled climate models (Stouffer et al., 2006) generally show AMOC weakening, but with a large spread in the reduction amplitude (1.59Sv). The spread could be due to the uncertainties in simulating different feedbacks from the atmosphere in climate models. In our ocean alone simulation the applied SSS restoring will certainly weaken the effect of added freshwater from GrIS and prevent us from quantifying the precise response of AMOC strength, although the simulated response is inside the uncertainty spread of climate models.

Here more attention is paid to the impact of GrIS freshwater on the variability of AMOC. The spectral analysis is applied to the time series of AMOC and shown in Figure 14. The spectral analysis reveals a decadal time scale of about 20 -yr period significant at $95 \%$ level in the control run, which was also suggested by other studies (Bentsen et al. 2004; Hu et al. 2004). The nature variability of AMOC on 
decadal time scale is dominated by a basin-scale adjustment to changes in the deep water convection sites in North Atlantic (Delworth et al. 1993, Bentsen et al. 2004, Mignot and Frankignoul, 2005). The significance of the 20 -yr period is clearly reduced in the water-hosing run. This implies that the added freshwater from GrIS melting has potential impact not only on the strength of AMOC but also on the strength of its variability. The high frequency variability (on interannual scale) does not change significantly, as its controlling factor, wind forcing, remains the same in our simulations (Jayne and Marotzke 2001; Shaffrey and Sutton 2004; Dong et al. 2009).

As discussed in section 3, the variability of AMOC, especially on decadal time scales, is linked to that of DWBC transport and deep convection (Figure 2). Figure $15 \mathrm{a}$ and $15 \mathrm{~b}$ show the spectra of DWBC transport at $53^{\circ} \mathrm{N}$ in the control and water-hosing runs, respectively. In the control run, the most pronounced period is $20-\mathrm{yr}$, consistent with that of the AMOC. This variability on decadal time scales almost collapses in the water-hosing run, which can explain the loss of significance in AMOC decadal variability.

In the calculation of DWBC transport we used the same definition $\left(\sigma_{\theta}>27.74\right.$ $\mathrm{kg} / \mathrm{m}^{3}$ ) for both experiments. With this definition, both the DWBC transport magnitude and the strength of its variability are significantly reduced in the waterhosing experiment. We also calculated the volume transport below a fixed depth $(1000 \mathrm{~m})$, and the significance of the variability turns out to be much higher than in Figure 15b, which can better explain the (weakened but not fully collapsed) 20 years variability in AMOC as shown in Figure 14b. This suggests that the definition of DWBC should be chosen according to the simulated scenario to study the variability of the Atlantic circulation and its predictability.

\section{Discussion and conclusions}

In this paper we evaluated FESOM on large time scales in a global configuration using the CORE inter-annual forcing. The focus is on the AMOC and the Arctic Ocean. The simulated AMOC strength and streamfunction structure agree with observational estimates and previous model simulations. The good correlation 
between the MLD in Labrador Sea, the DWBC transport at $53^{\circ} \mathrm{N}$ and the AMOC index at $45^{\circ} \mathrm{N}$ indicates that the DWBC represents a signal of primarily thermohaline origin and it sets the variability of the AMOC downstream (e.g., Böning et al., 2006). The MLD in the Labrador Sea leads the AMOC at $45^{\circ} \mathrm{N}$ by about 2 years in our simulation, consistent to previous studies (e.g., Eden and Greatbatch, 2003).

The model well represents the summer and winter sea ice concentration in the Arctic Ocean. The most pronounced bias from observation is in the marginal seas in summertime, with overestimated sea ice concentration. The simulated liquid freshwater content in the Arctic Ocean has an increasing trend during the spinup phase as reported in other models, while its variability (after the model spinup), controlled mainly by freshwater exchange through the Arctic gateways, is similar to that shown in previous studies (Häkkinen and Proshutinsky, 2004; Köberle and Gerdes, 2007; Lique et al., 2009).

A water-hosing experiment with $0.1 \mathrm{~Sv}$ anomalous freshwater from GrIS melting is conducted to study the direct ocean response. The added freshwater mainly resides in the North Atlantic, Arctic Ocean and the west South Atlantic after 120 model years simulation. The highest concentration is in the North Atlantic subpolar gyre. The ocean salinity decreases accordingly, with a pattern similar to that of the GrIS freshwater distribution. The ocean dynamical adjustment also leads to significant negative salinity anomaly in the eastern North Atlantic, similar to the result from an intermediate complexity climate model (Gerdes et al., 2006).

The DSL anomaly can be carried to the global ocean from the North Atlantic by both wave and advection processes (Stammer, 2008). After about 20 years, DSL changes can be observed in all basins. However, the DSL rise is the most significant in the North Atlantic and Arctic Ocean. The largest DSL rise is in the northwest North Atlantic, reaching more than $30 \mathrm{~cm}$ after 120 model years, consistent with previous model studies (Stammer 2008; Yin et al. 2009; Hu et al. 2009; Kopp et al., 2010). As in most previous studies, the barotropic signal (e.g., discussed by Lorbacher et al., 2012), which spreads the melt water signal within 
days around the globe, is ignored in this work by excluding the direct contribution to sea level from the anomalous water mass.

The liquid freshwater content in the Arctic Ocean increases considerably with time in the water-hosing experiment. The freshening is obvious in all Arctic basins, with the Eurasian Basin having the largest salinity anomaly. The adjusted ocean circulation leads to changes in surface freshwater distribution. Due to changes in the sea level gradient between the Arctic Ocean and the sub-arctic seas, the exchange fluxes through all Arctic gates are reduced. On one side the linkage between the North Pacific and North Atlantic through the Bering Strait and Arctic Ocean is weakened, on another side the North Atlantic receives much less freshwater from the Arctic Ocean and the North Atlantic water mass can even enter the Canadian Basin through the CAA straits. These changes imply changes in the role of the Arctic Ocean for the global climate, which need to be further explored in the future. The simulated sea ice state does not change noticeably in the water-hosing experiment (not shown), because of missing atmospheric feedbacks.

The anomalous freshwater leads to reduction in both the AMOC strength (e.g., Stouffer et al., 2006; Swingedouw et al., 2006, Gerdes et al., 2006; Hu et al., 2009 ) and the strength of its decadal variability. The decadal variability of the DWBC becomes much weaker in the water-hosing experiment, leading to significant reduction in the $20 \mathrm{yr}$ period oscillation indicated by AMOC. In our experiment the GrIS freshwater is only added in warm seasons, with the assumption that the ice sheet does not melt in winter even in the global warming scenario. If the same amount of melt water is evenly distributed over the year, the AMOC and its variability is found to be even lower (in a sensitivity experiment, not shown), which is not surprising as the deep convection happens mainly in winter.

Our analysis suggests that care should be taken for using some (commonly used) indices, like DWBC and MLD, in the scenario of increased freshwater forcing. Otherwise, the information can be incomplete. For example, we often define the MLD as the depth where the potential density anomaly referenced to the surface 
density reaches some chosen value. In this case, the MLD in the Labrador Sea becomes lower at the beginning of the water-hosing experiment compared to the control run and then starts to recover with time. The reason is that the ocean surface becomes fresher at the beginning, reducing the MLD, while the deep ocean also becomes fresher later, recovering the MLD. However, the AMOC in the water-hosing experiment is permanently lower (Figure 12), so the change of MLD due to the anomalous freshwater input cannot be used alone as an indicator of AMOC change, although in the control run we can use MLD to explain the variability of AMOC (Figure 2).

This work shows that FESOM can reproduce the past ocean variability and well simulate the impact of possible GrIS melting under global warming, despite its unique numerical approach. However, missing atmospheric feedbacks and applying SSS restoring in ocean hindcast simulations can certainly affect the robustness in the representation of variability (Gerdes et al., 2006, Griffies et al., 2009). The large range of responses to identical surface freshwater flux anomalies under different forms of sea surface boundary conditions leads Gerdes et al. (2006) to suggest the development of simple atmospheric models to be used in ocean experiments in order to understand the behavior of ocean models. The idea to find solutions for evaluating ocean models with adequate forms of surface boundary conditions but without the full complexity of couple climate models is also proposed by the international ocean modeling community (e.g., in the COREs project), and we expect that the progress in this direction through international cooperation can help improve and develop ocean models in the future, thus contributing to reduce uncertainties in climate models in the end. 


\section{Reference}

Bentsen M, Drange H, Furevik T, Zhou T (2004) Simulated variability of the Atlantic meridional overturning circulation. Climate Dynamics 22 (6-7):701-720

Böning CW, Scheinert M, Dengg J, Biastoch A, Funk A (2006) Decadal variability of subpolar gyre transport and its reverberation in the North Atlantic overturning. Geophys Res Lett 33 (21):L21S01

Bower AS, Lozier MS, Gary SF, Böning CW (2009) Interior pathways of the North Atlantic meridional overturning circulation. Nature 459 (7244):243-247

Cavalieri D, C. Parkinson, P. Gloersen, and H. J. Zwally (1996, updated yearly) Sea ice concentrations from Nimbus-7 SMMR and DMSP SSM/I-SSMIS passive microwave data. National Snow and Ice Data Center (Digital media)

Conkright M, Levitus S, Antonov J, Baranova O, Boyer T, Garcia H, Gelfeld R, Johnson D, Locarnini R, O'Brien T, Smolyar I, Stephens C (2001) World ocean database 2001 and world ocean atlas 2001. American Geophysical Union, Washington

Cunningham S, Baringer M, Johns B, Toole J, Osterhaus S, Fischer J, Piola A, McDonagah E, Lozier S, Send U (2010) The present and future system for measuring the Atlantic meridional overturning circulation and heat transport. In: Proceedings of the "OceanObs'09: Sustained Ocean Observations and Information for Society" Conference. ; 2 Hall, J., Harrison, D. E. and Stammer, D. (eds); ESA Publication, 2. OceanObs'09, Venice, Italy.

Danilov S, Kivman G, Schröter J (2004) A finite-element ocean model: principles and evaluation. Ocean modelling $6(2): 125-150$

Delworth T, Manabe S, Stouffer R (1993) Interdecadal variations of the thermohaline circulation in a coupled ocean-atmosphere model. Journal of Climate 6 (11):1993-2011

Dong S, Garzoli S, Baringer M, Meinen C, Goni G (2009) Interannual variations in the Atlantic meridional overturning circulation and its relationship with the net northward heat transport in the South Atlantic. Geophys Res Lett 36 (20):L20606

Eden C, Greatbatch RJ (2003) A damped decadal oscillation in the North Atlantic climate system. Journal of Climate 16 (24):4043-4060

Fichefet T, Poncin C, Goosse H, Huybrechts P, Janssens I, Le Treut H (2003) Implications of changes in freshwater flux from the Greenland ice sheet for the climate of the 21 st century. Geophys Res Lett 30 (17):1911

Gent PR, Mcwilliams JC (1990) Isopycnal mixing in ocean circulation models. Journal of Physical Oceanography 20 (1):150-155

Gerdes R, Hurlin W, Griffies SM (2006) Sensitivity of a global ocean model to increased run-off from Greenland. Ocean modelling 12 (3):416-435

Gower J (2010) Comment on "Response of the global ocean to Greenland and Antarctic ice melting” by D. Stammer. Journal of Geophysical Research 115 (C10):C10009 Greatbatch RJ (1994) A note on the representation of steric sea level in models that conserve volume rather than mass. Journal of Geophysical Research -All Series- 99:12-12 
Griffies SM, Biastoch A, Böning C, Bryan F, Danabasoglu G, Chassignet EP, England MH, Gerdes R, Haak H, Hallberg RW (2009) Coordinated ocean-ice reference experiments (COREs). Ocean modelling $26(1-2): 1-46$

Griffies SM, Greatbatch RJ (2012) Physical processes that impact the evolution of global mean sea level in ocean climate models. Ocean modelling 51:37-72

Hakkinen S, Proshutinsky A (2004) Freshwater content variability in the Arctic Ocean. J. Geophys. Res. 109: C03051

Houssais MN, Herbaut C (2011) Atmospheric forcing on the Canadian Arctic Archipelago freshwater outflow and implications for the Labrador Sea variability. J Geophys Res 116:C00D02 Hu A, Meehl GA, Han W, Yin J (2009) Transient response of the MOC and climate to potential melting of the Greenland Ice Sheet in the 21st century. Geophys Res Lett 36 (10):L10707 $\mathrm{Hu}$ A, Meehl GA, Han W, Yin J (2011) Effect of the potential melting of the Greenland Ice Sheet on the Meridional Overturning Circulation and global climate in the future. Deep Sea Research Part II: Topical Studies in Oceanography, 58, 1914-1926, doi:10.1016/j.dsr2.2010.10.069 $\mathrm{Hu}$ A, Meehl GA, Washington WM, Dai A (2004) Response of the Atlantic thermohaline circulation to increased atmospheric $\mathrm{CO}_{2}$ in a coupled model. Journal of Climate 17 (21):42674279 Jayne SR, Marotzke J (2001) The dynamics of ocean heat transport variability. Rev. Geophys., 39(3), 385-411, doi:10.1029/2000RG000084

Jungclaus JH, Haak H, Esch M, Roeckner E, Marotzke J (2006) Will Greenland melting halt the thermohaline circulation? Geophysical research letters 33 (17):L17708

Köberle C, Gerdes R (2007) Simulated variability of the arctic ocean freshwater balance 19482001. Journal of Physical Oceanography 37 (6):1628-1644

Kopp RE, Mitrovica JX, Griffies SM, Yin J, Hay CC, Stouffer RJ (2010) The impact of Greenland melt on local sea levels: a partially coupled analysis of dynamic and static equilibrium effects in idealized water-hosing experiments. Climatic change 103 (3):619-625

Large W, Yeager S (2009) The global climatology of an interannually varying air-sea flux data set. Climate Dynamics 33 (2):341-364

Large WG, Yeager SG (2004) Diurnal to decadal global forcing for ocean and sea-ice models: the data sets and flux climatologies. National Center for Atmospheric Research

Latif M, Böning C, Willebrand J, Biastoch A, Dengg J, Keenlyside N, Schweckendiek U, Madec $\mathrm{G}$ (2006) Is the thermohaline circulation changing? Journal of Climate 19 (18):4631-4637

Lique C, Treguier AM, Scheinert M, Penduff T (2009) A model-based study of ice and freshwater transport variability along both sides of Greenland. Climate Dynamics 33 (5):685-705

Lorbacher K., Marsland SJ, Church JA, Griffies MS, and Stammer D (2012) Rapid barotropic sea level rise from ice sheet melting. J. Geophys. Res., 117, C06003, doi:10.1029/2011JC007733 Lumpkin R, Speer K (2003) Large-scale vertical and horizontal circulation in the North Atlantic Ocean. Journal of Physical Oceanography 33 (9):1902-1920

Lumpkin R, Speer KG, Koltermann KP (2008) Transport across 48 N in the Atlantic Ocean. Journal of Physical Oceanography 38 (4):733-752 
Marsh R, Desbruyeres D, Bamber J, De Cuevas B, Coward A, Aksenov Y (2010) Short-term impacts of enhanced Greenland freshwater fluxes in an eddy-permitting ocean model. Ocean Science 6 (3):749-760

Mignot J, Frankignoul C (2005) The Variability of the Atlantic Meridional Overturning Circulation, the North Atlantic Oscillation, and the the El Niño-Southern Oscillation in the Bergen Climate Model. Journal of Climate 18 (13):2361-2375

Pacanowski R, Philander S (1981) Parameterization of vertical mixing in numerical models of tropical oceans. Journal of Physical Oceanography 11 (11):1443-1451

Palter JB, Lozier MS, Lavender KL (2008) How does Labrador Sea Water enter the deep western boundary current? Journal of Physical Oceanography 38 (5):968-983

Redi MH (1982) Oceanic isopycnal mixing by coordinate rotation. Journal of Physical Oceanography 12 (10):1154-1158

Shaffrey L, Sutton R (2004) The interannual variability of energy transports within and over the Atlantic Ocean in a coupled climate model. Journal of Climate 17 (7):1433-1448

Sidorenko D, Wang Q, Danilov S, Schröter J (2011) FESOM under coordinated ocean-ice reference experiment forcing. Ocean Dynamics 61 (7):881-890. doi:10.1007/s10236-011-0406-7 Slangen ABA, Katsman CA, Wal RSW van de, Vermeersen LLA, Riva REM (2012) Towards regional projections of twenty-first century sea-level change based on IPCC SRES scenario.

Climate Dynamics 38 (5-6):1191-1209

Stammer D (2008) Response of the global ocean to Greenland and Antarctic ice melting. J.

Geophys. Res., 113, C06022, doi:10.1029/2006JC004079

Stammer D, Agarwal N, Herrmann P, Köhl A, Mechoso C (2011) Response of a Coupled OceanAtmosphere Model to Greenland Ice Melting. Surveys in geophysics, 32 (4): 621-642

Stouffer R, Yin J, Gregory J, Dixon K, Spelman M, Hurlin W, Weaver A, Eby M, Flato G, Hasumi H (2006) Investigating the causes of the response of the thermohaline circulation to past and future climate changes. Journal of Climate 19 (8):1365-1387

Swingedouw D, Braconnot P, Delecluse P, Guilyardi E, Marti O (2007) Quantifying the AMOC feedbacks during a $2 \times \mathrm{CO}_{2}$ stabilization experiment with land-ice melting. Climate Dynamics 29 (5):521-534

Swingedouw D, Braconnot P, Marti O (2006) Sensitivity of the Atlantic Meridional Overturning Circulation to the melting from northern glaciers in climate change experiments. Geophysical research letters 33 (7):L07711

Timmermann R, Danilov S, Schröter J, Böning C, Sidorenko D, Rollenhagen K (2009) Ocean circulation and sea ice distribution in a finite element global sea ice-ocean model. Ocean modelling 27 (3-4):114-129

Timmermann R, Hellmer H, Beckmann A (2002) Simulations of ice-ocean dynamics in the Weddell Sea 2. Interannual variability 1985-1993. J. Geophys. Res., 107, 3025, doi: 10.1029/2000JC000742

Wang Q, Danilov S, Schröter J (2008) Finite element ocean circulation model based on triangular prismatic elements, with application in studying the effect of topography representation. $\mathrm{J}$

Geophys Res 113:C05015 
Yin J, Schlesinger ME, Stouffer RJ (2009) Model projections of rapid sea-level rise on the northeast coast of the United States. Nature Geoscience 2 (4):262-266 


\section{Figure captions}

Figure 1. (a) Time series of the AMOC index for the four cycles in the control run (time axis is made continues). The index is defined as the maximum of the annual mean AMOC streamfunction at $45^{\circ} \mathrm{N}$. (b) AMOC streamfunction averaged over the last 10 years in the control run.

Figure 2. (a) Anomalies of the Deep Western Boundary Current (DWBC) transport at $53^{\circ} \mathrm{N}$ and the mixed layer depth (MLD) in the Labrador Sea in the fourth cycle of the control run. (b) The same as (a) but for the DWBC transport and the Atlantic Meridional Overturning Circulation (AMOC) index at $45^{\circ} \mathrm{N}$.

Figure 3. Simulated mean sea ice concentration in (a) March and (c) September, compared to NSIDC datasets in (b) March and (d) September. The average period is between 1989 and 2007.

Figure 4. (a) The anomaly of the total Arctic liquid freshwater content $\left[\mathrm{m}^{3}\right]$ in the last model cycle of the control run, (b) Arctic freshwater content derivative and the anomaly of the total freshwater flux though all gates of the Arctic Ocean.

Figure 5. Annual mean dynamic sea level anomaly for model year 2, 4, 6, 10, 15, 20. The anomaly is calculated by subtracting the control run result from the water-hosing run result. Note the nonuniform color scales.

Figure 6. Mean dynamic sea level change for model year (left) 50-60 and (right) 110-120. The change is calculated by subtracting the control run result from the water-hosing run result.

Figure 7. (a) GrIS melt water passive tracer and (b) salinity difference between the water-hosing and control runs. From top to bottom are for the surface, $1000 \mathrm{~m}$ depth [psu] and the vertically integrated value $[\mathrm{psu} \cdot \mathrm{m}]$. The mean fields over the last 10 model years are plotted.

Figure 8. Mean kinetic energy at surface averaged over the last 10 model years in (a) control and (b) water-hosing runs on logarithmic scale.

Figure 9. Vertically integrated (a) passive tracer $[\mathrm{psu} \bullet \mathrm{m}]$ and (b) salinity anomaly $[\mathrm{psu} \bullet \mathrm{m}]$ averaged over the last 10 model years. The integration is from ocean surface to bottom. (c)(d) are the same as (a)(b), but for the integration over the upper $200 \mathrm{~m}$ depth. 
Figure 10. Vertical transect of (a) passive tracer [psu] and (b) salinity anomaly [psu] averaged over the last 10 model years. The location of the transect is shown in Figure 9a.

Figure 11. (a) Dynamic sea level anomaly [cm] and (b) barotropic streamfunction anomaly [Sv] averaged over the last 10 model years.

Figure 12. Time-series of total liquid freshwater content $\left[\mathrm{m}^{3}\right]$ in the Arctic Ocean for the control (blue) and water-hosing (red) runs. The dashed line represents a second order polynomial fitting the red line.

Figure 13. AMOC index at $45^{\circ} \mathrm{N}$ in the control run (blue) and water-hosing run (red).

Figure 14. Power spectra of AMOC (blue line) in the (a) control run and (b) water-hosing run. The red dashed line represents the $95 \%$ confidence level.

Figure 15. Power spectra of DWBC transport (blue line) in the (a) control run and (b) water-hosing run. The red dashed line represents the $95 \%$ confidence level. 


\section{Tables and figures}

Table 1. Total volume transport [Sv] through the Arctic gateways.

\begin{tabular}{|l|l|l|l|l|}
\hline & Fram Strait & Barents Sea & Bering Strait & Davis Strait \\
\hline control & -3.7 (in 2.5, out 6.2) & 3.3 & 1 & $\mathbf{- 0 . 6}$ \\
\hline water-hosing & -3.7 (in 2.2, out 5.9) & 3 & $\mathbf{0 . 8}$ & $\mathbf{- 0 . 1}$ \\
\hline
\end{tabular}
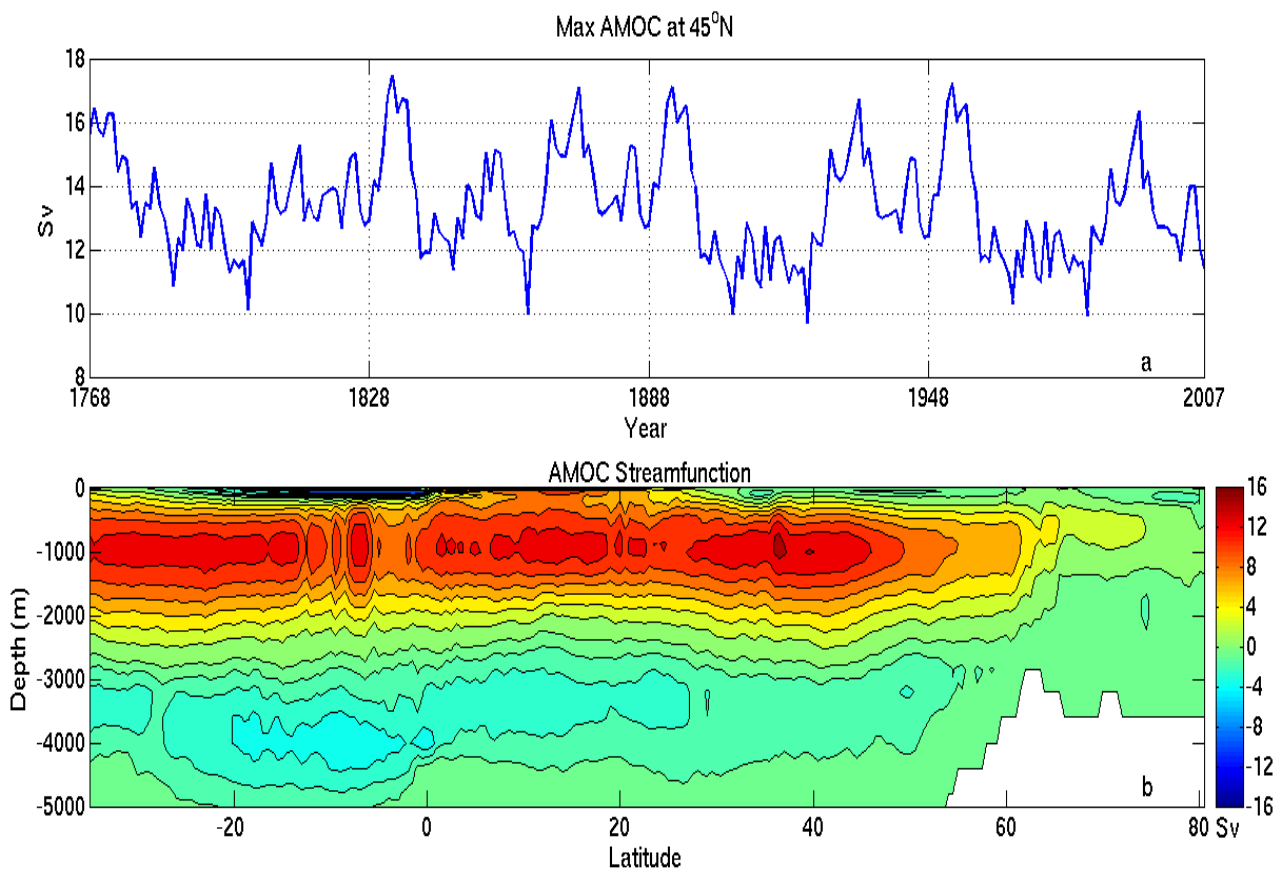

Figure 1. (a) Time series of the AMOC index for the four cycles in the control run (time axis is made continues). The index is defined as the maximum of the annual mean AMOC streamfunction at $45^{\circ} \mathrm{N}$. (b) AMOC streamfunction averaged over the last 10 years in the control run.
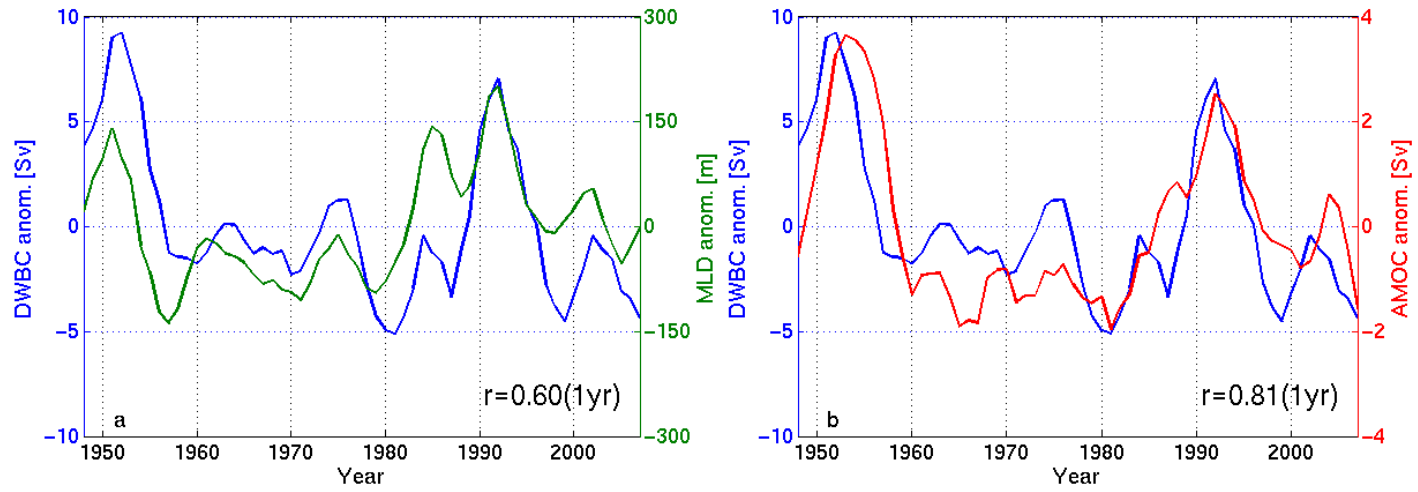

Figure 2. (a) Anomalies of the Deep Western Boundary Current (DWBC) transport at $53^{\circ} \mathrm{N}$ and the mixed layer depth (MLD) in the Labrador Sea in the fourth cycle of the control run. (b) The same as (a) but for the DWBC transport and the Atlantic Meridional Overturning Circulation (AMOC) index at $45^{\circ} \mathrm{N}$. 


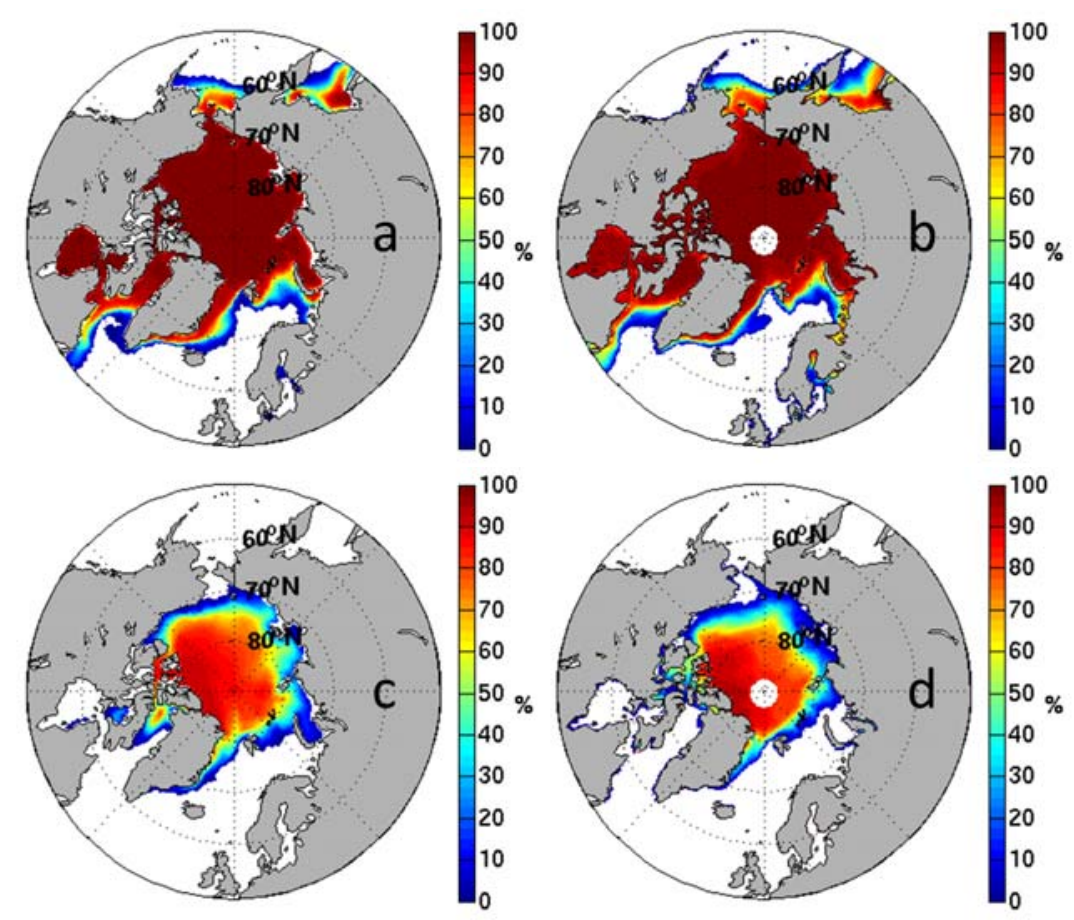

Figure 3. Simulated mean sea ice concentration in (a) March and (c) September, compared to NSIDC datasets in (b) March and (d) September. The average period is between 1989 and 2007.

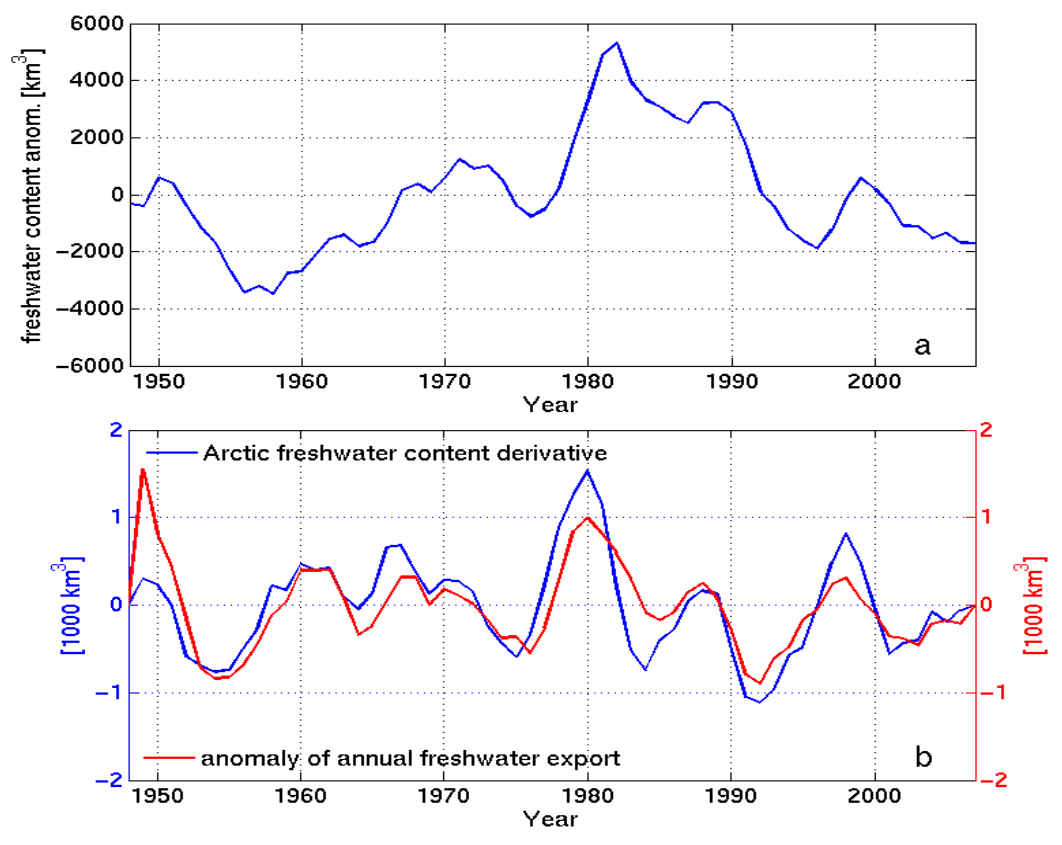

Figure 4. (a) The anomaly of the total Arctic liquid freshwater content $\left[\mathrm{m}^{3}\right]$ in the last model cycle of the control run, (b) Arctic freshwater content derivative and the anomaly of the total freshwater flux though all gates of the Arctic Ocean. 

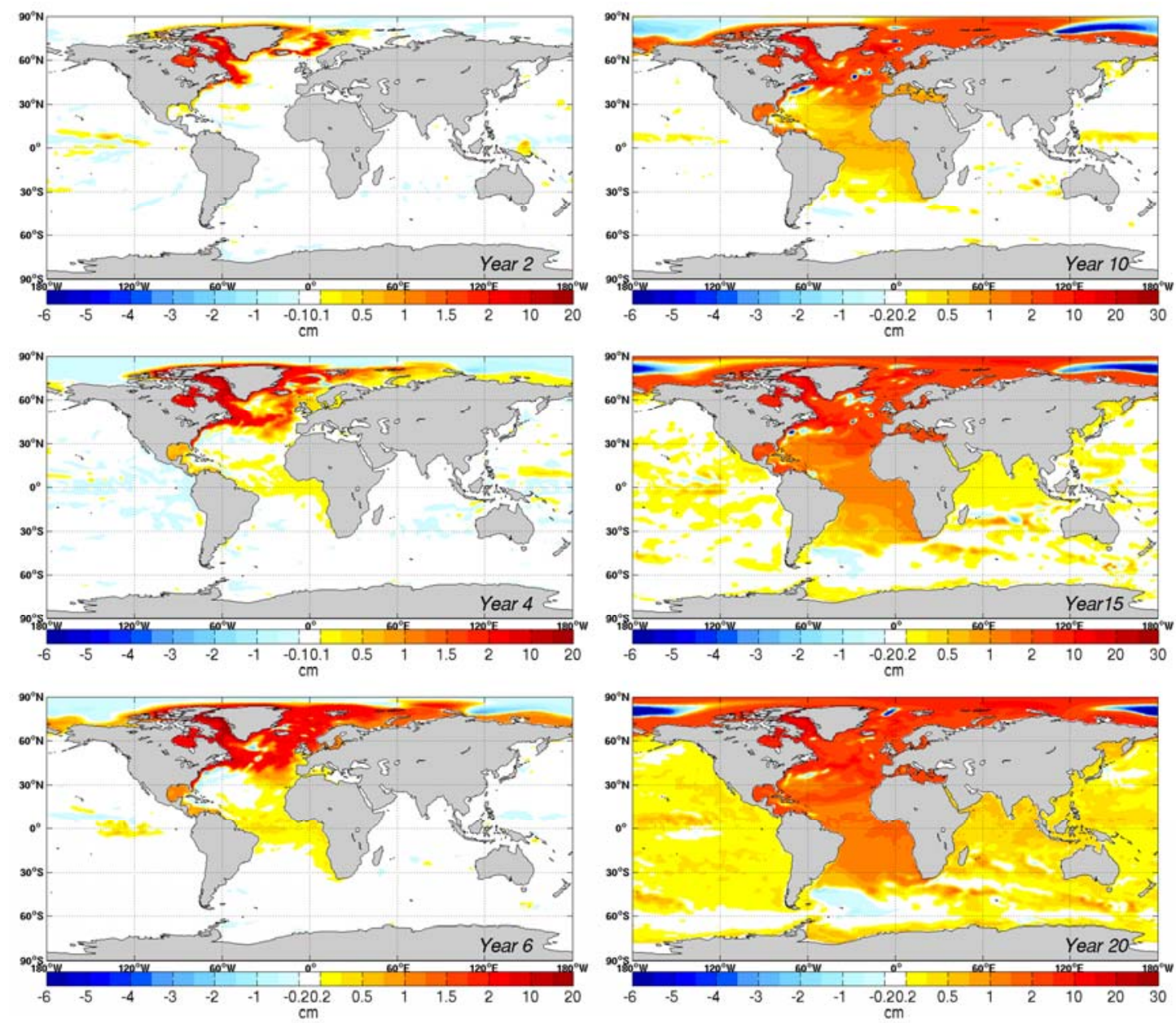

Figure 5. Annual mean dynamic sea level anomaly for model year 2, 4, 6, 10, 15, 20. The anomaly is calculated by subtracting the control run result from the water-hosing run result. Note the nonuniform color scales.
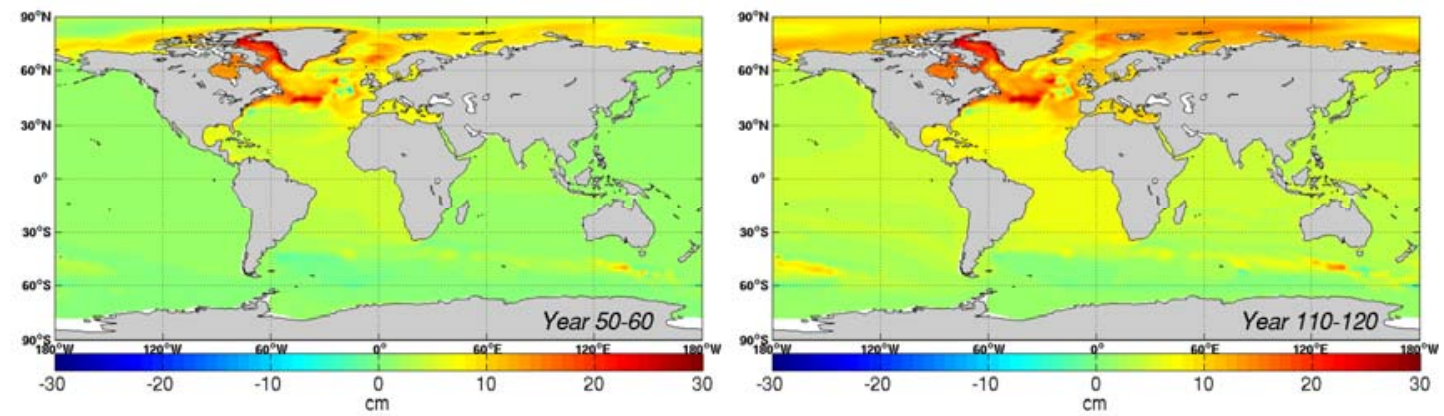

Figure 6. Mean dynamic sea level change for model year (left) 50-60 and (right) 110-120. The change is calculated by subtracting the control run result from the water-hosing run result. 
a
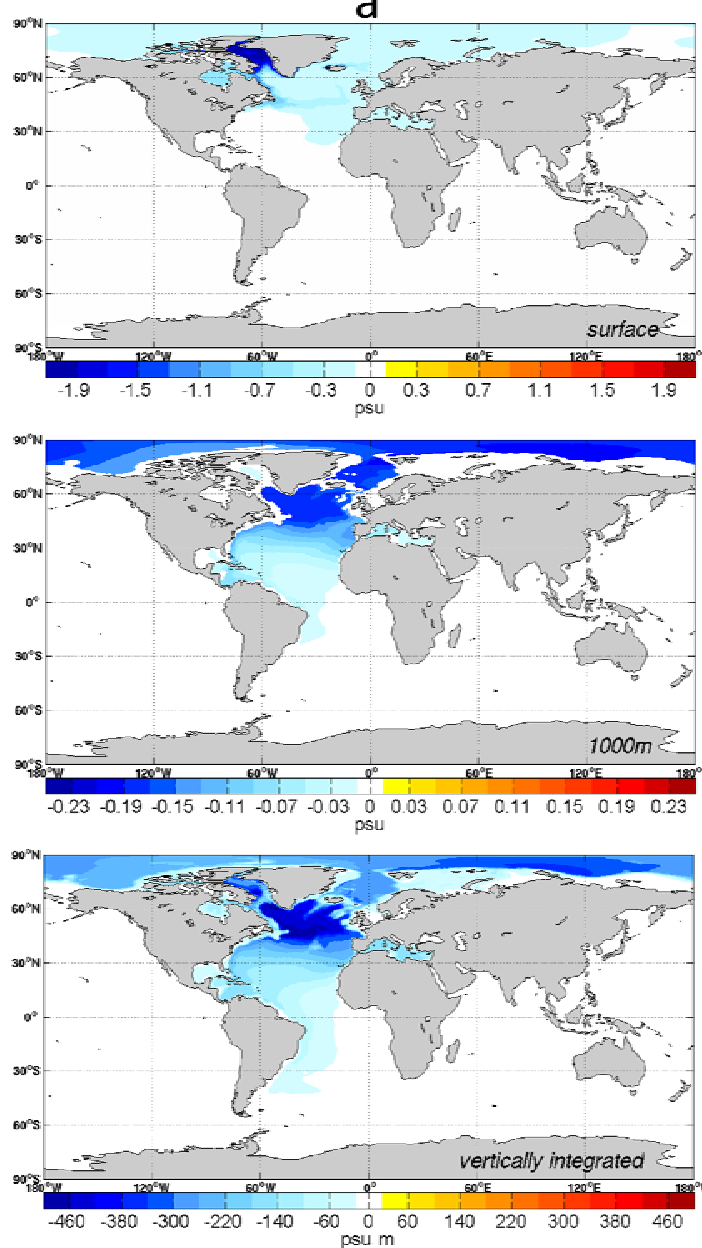

b
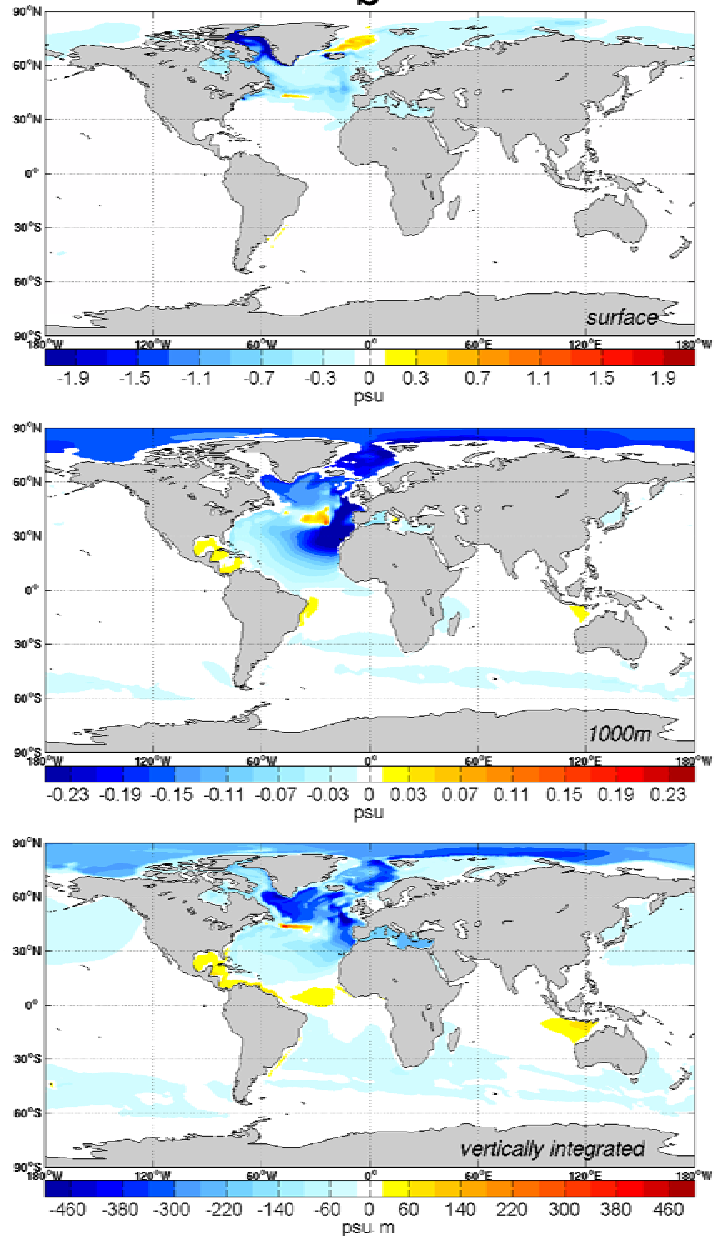

Figure 7. (a) GrIS melt water passive tracer and (b) salinity difference between the water-hosing and control runs. From top to bottom are for the surface, $1000 \mathrm{~m}$ depth [psu] and the vertically integrated value $[\mathrm{psu} \cdot \mathrm{m}]$. The mean fields over the last 10 model years are plotted.

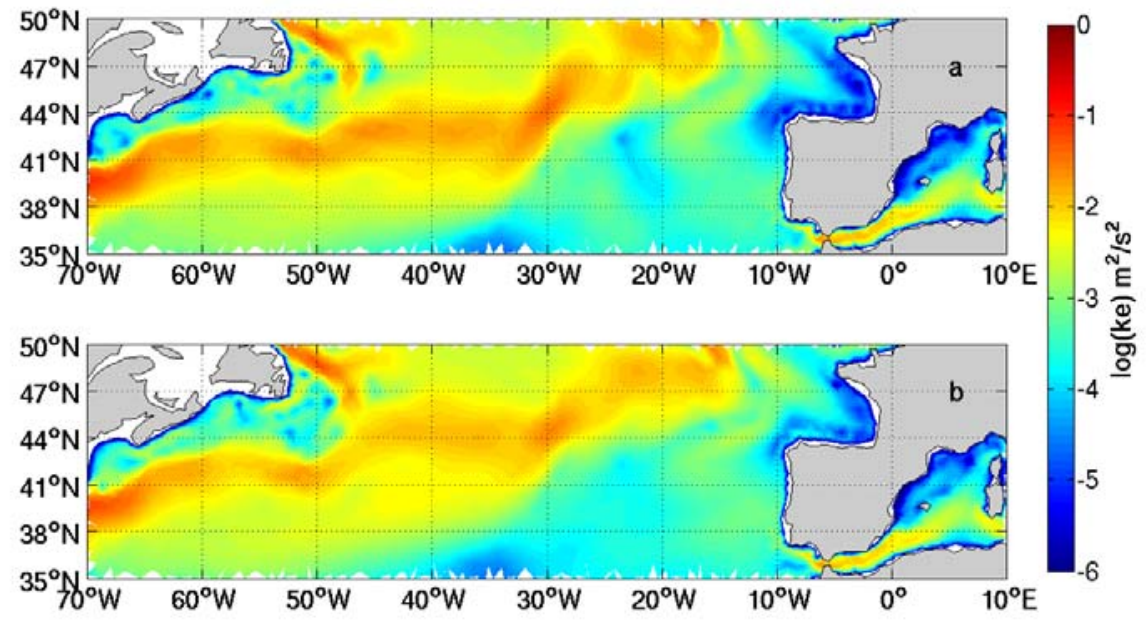

Figure 8. Mean kinetic energy at surface averaged over the last 10 model years in (a) control and (b) water-hosing runs on logarithmic scale. 

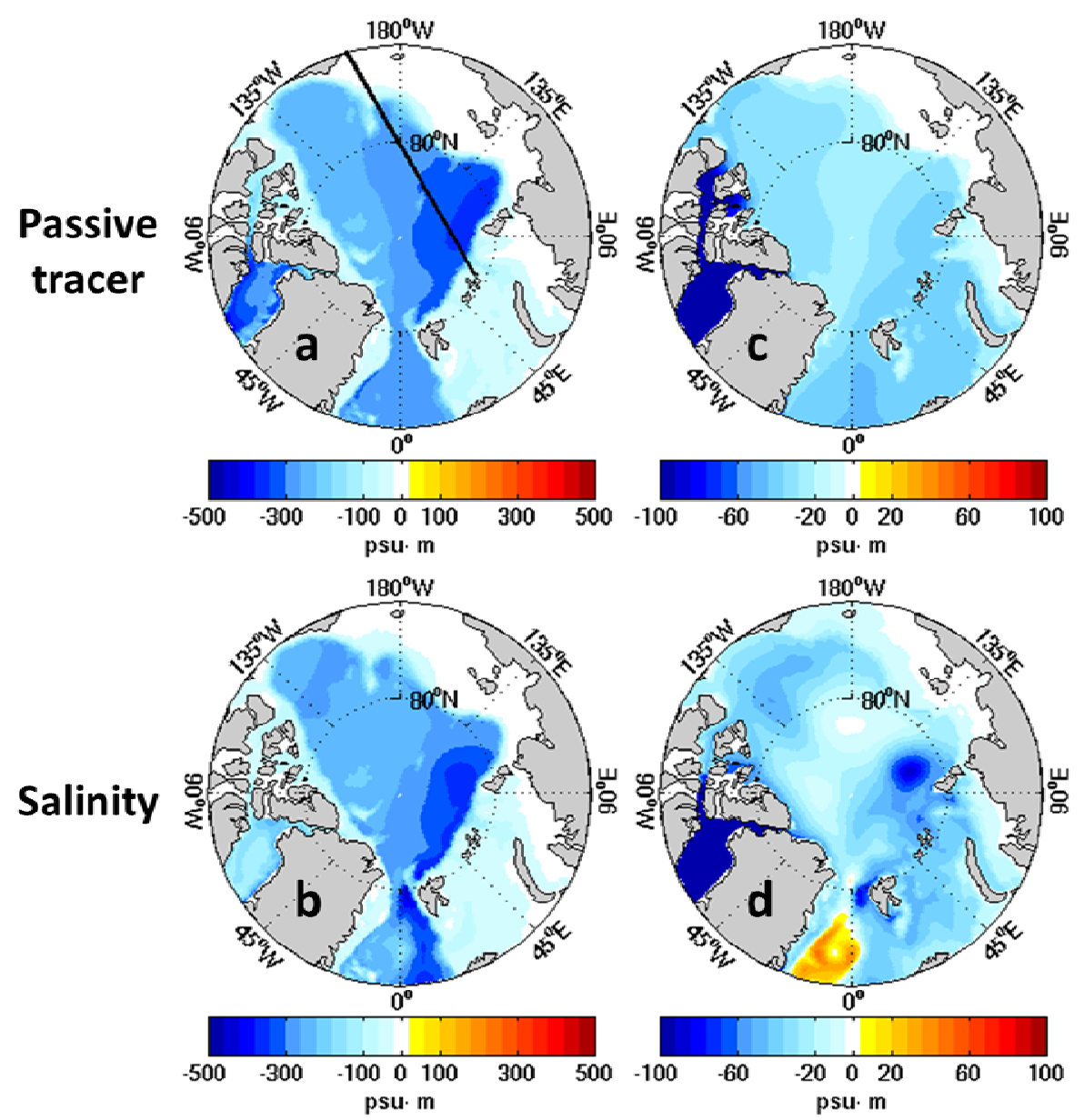

Figure 9. Vertically integrated (a) passive tracer $[\mathrm{psu} \cdot \mathrm{m}]$ and (b) salinity anomaly [psu $\bullet \mathrm{m}]$ averaged over the last 10 model years. The integration is from ocean surface to bottom. (c)(d) are the same as (a)(b), but for the integration over the upper $200 \mathrm{~m}$ depth.

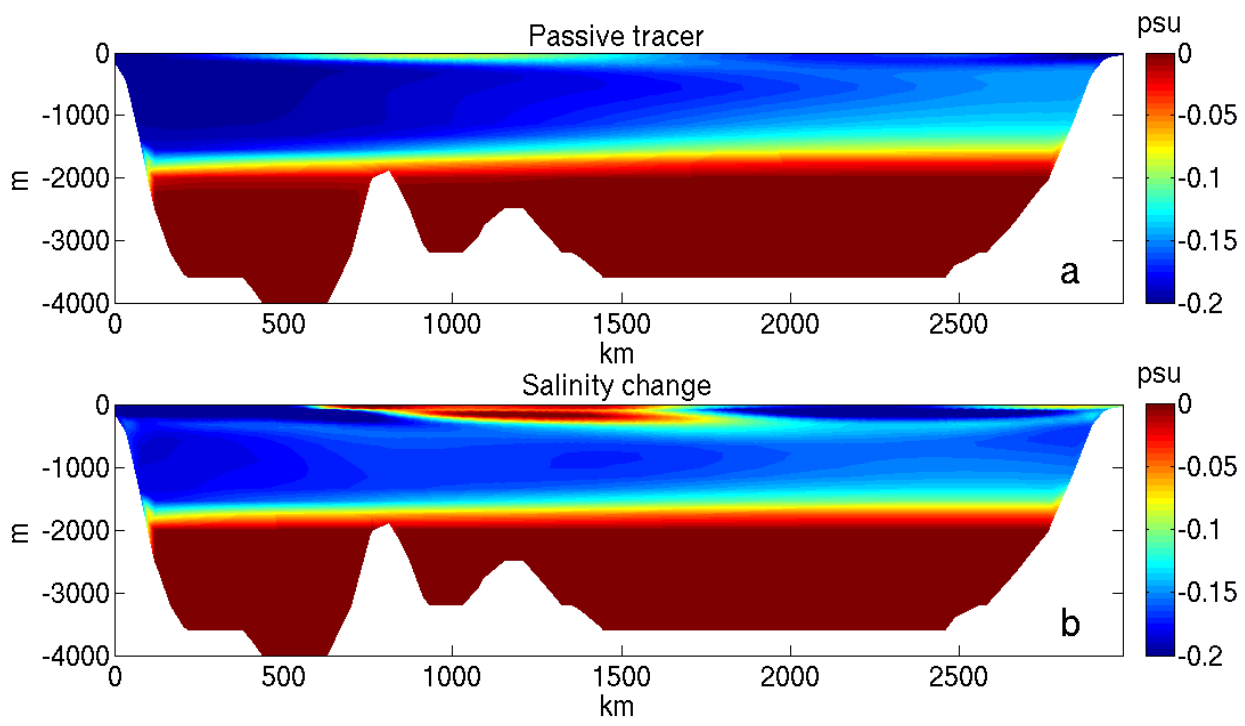

Figure 10. Vertical transect of (a) passive tracer [psu] and (b) salinity anomaly [psu] averaged over the last 10 model years. The location of the transect is shown in Figure 9a. 


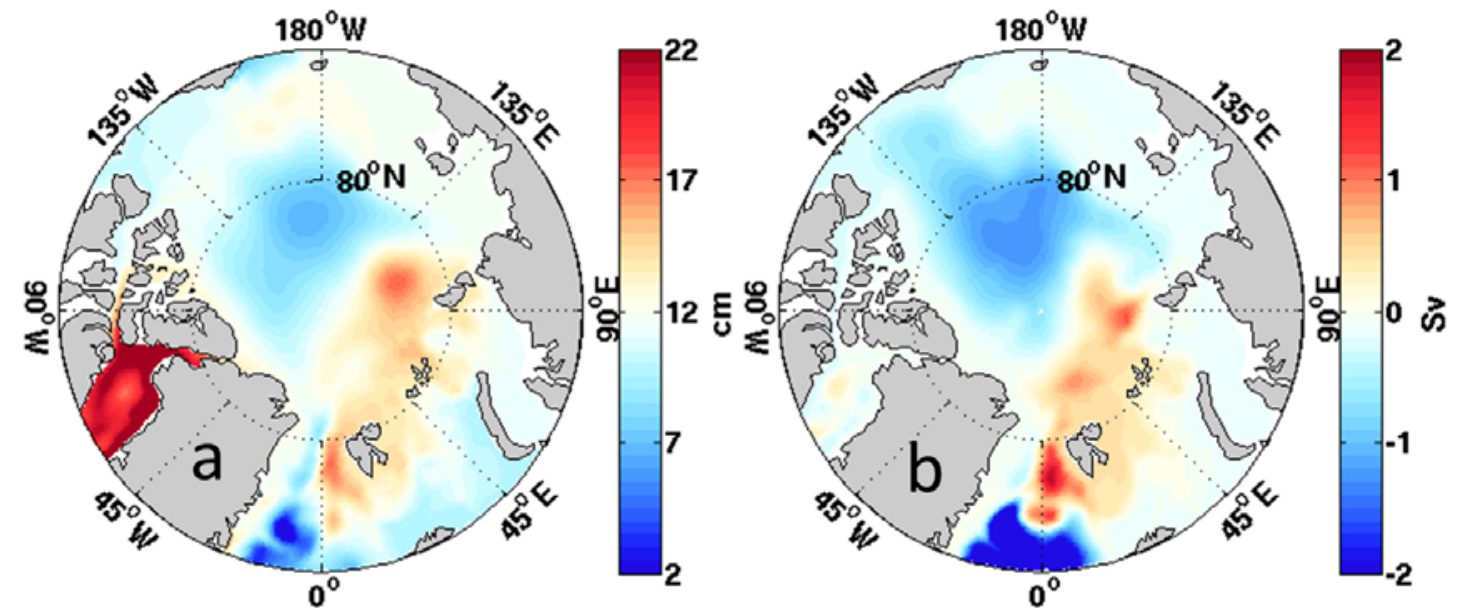

Figure 11. (a) Dynamic sea level anomaly [cm] and (b) barotropic streamfunction anomaly [Sv] averaged over the last 10 model years.

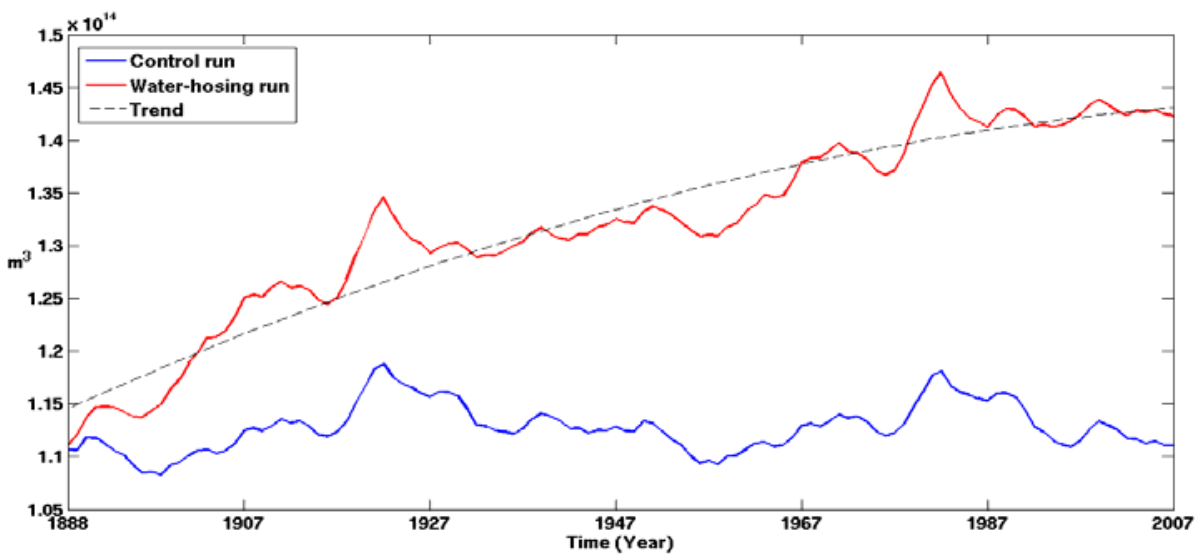

Figure 12. Time-series of total liquid freshwater content $\left[\mathrm{m}^{3}\right]$ in the Arctic Ocean for the control (blue) and water-hosing (red) runs. The dashed line represents a second order polynomial fitting the red line.

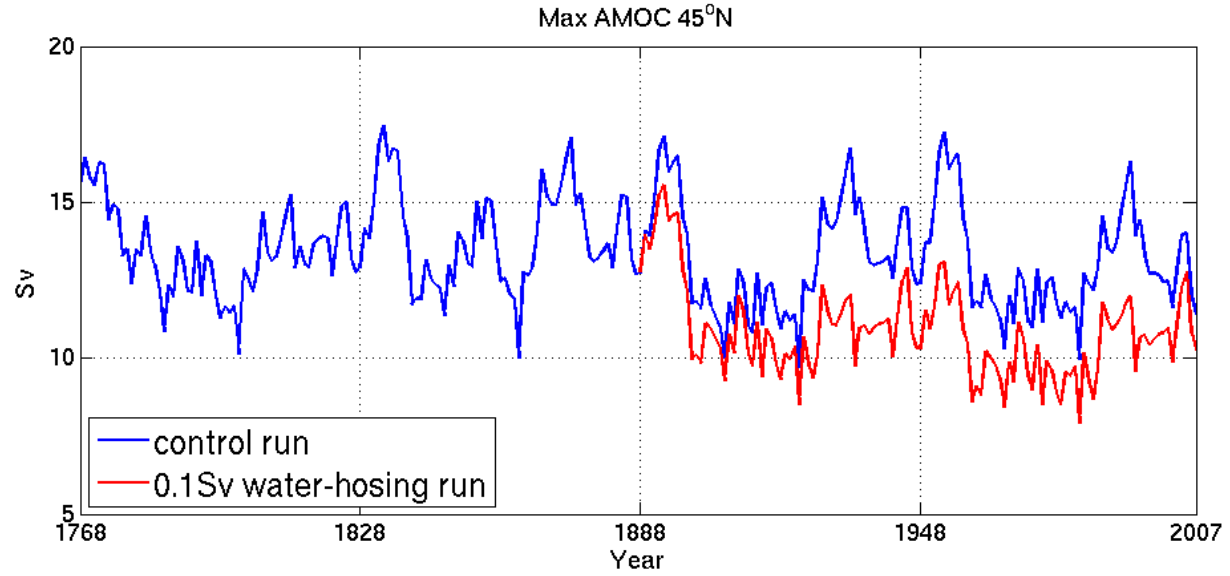

Figure $13 . \mathrm{AMOC}$ index at $45^{\circ} \mathrm{N}$ in the control run (blue) and water-hosing run (red). 

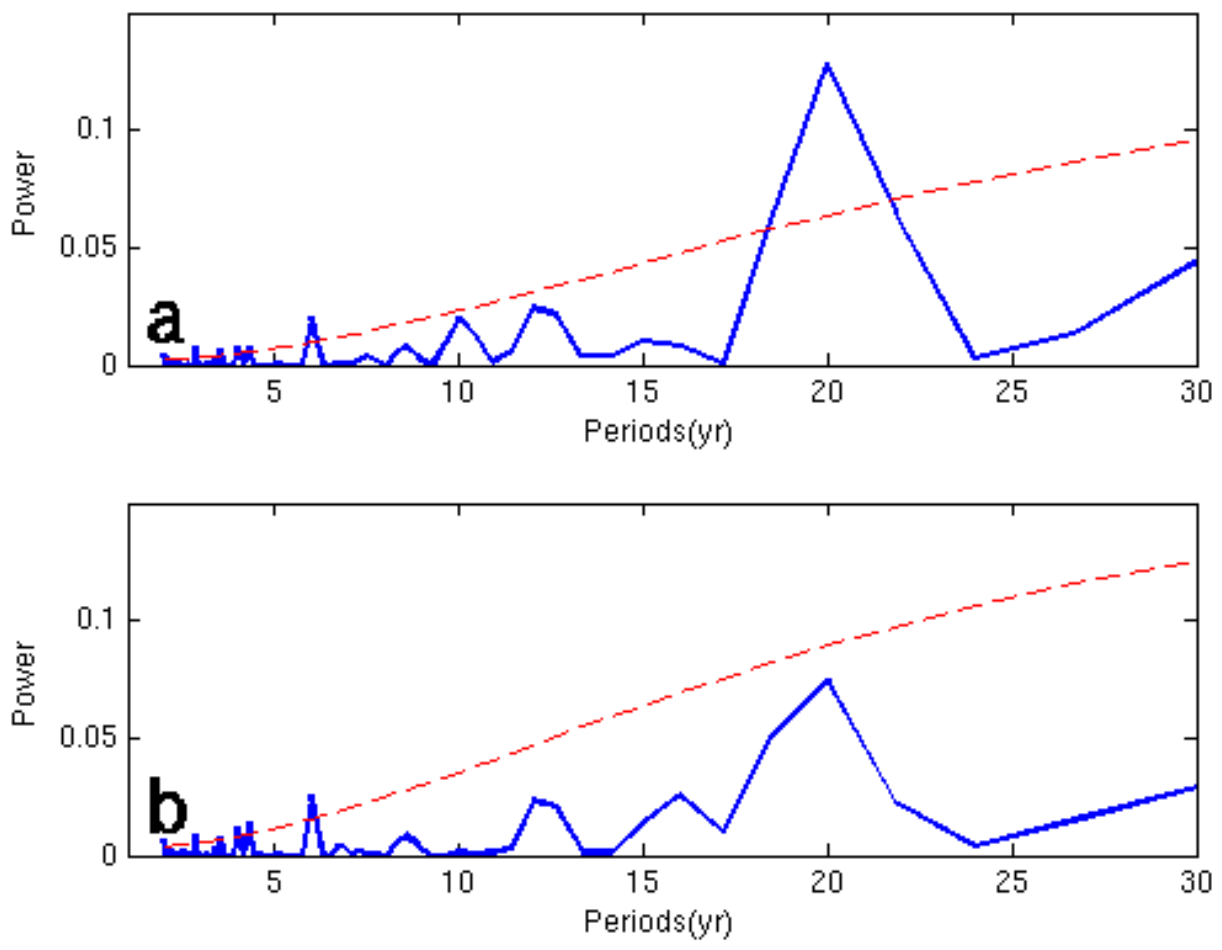

Figure 14. Power spectra of AMOC (blue line) in the (a) control run and (b) water-hosing run. The red dashed line represents the $95 \%$ confidence level.
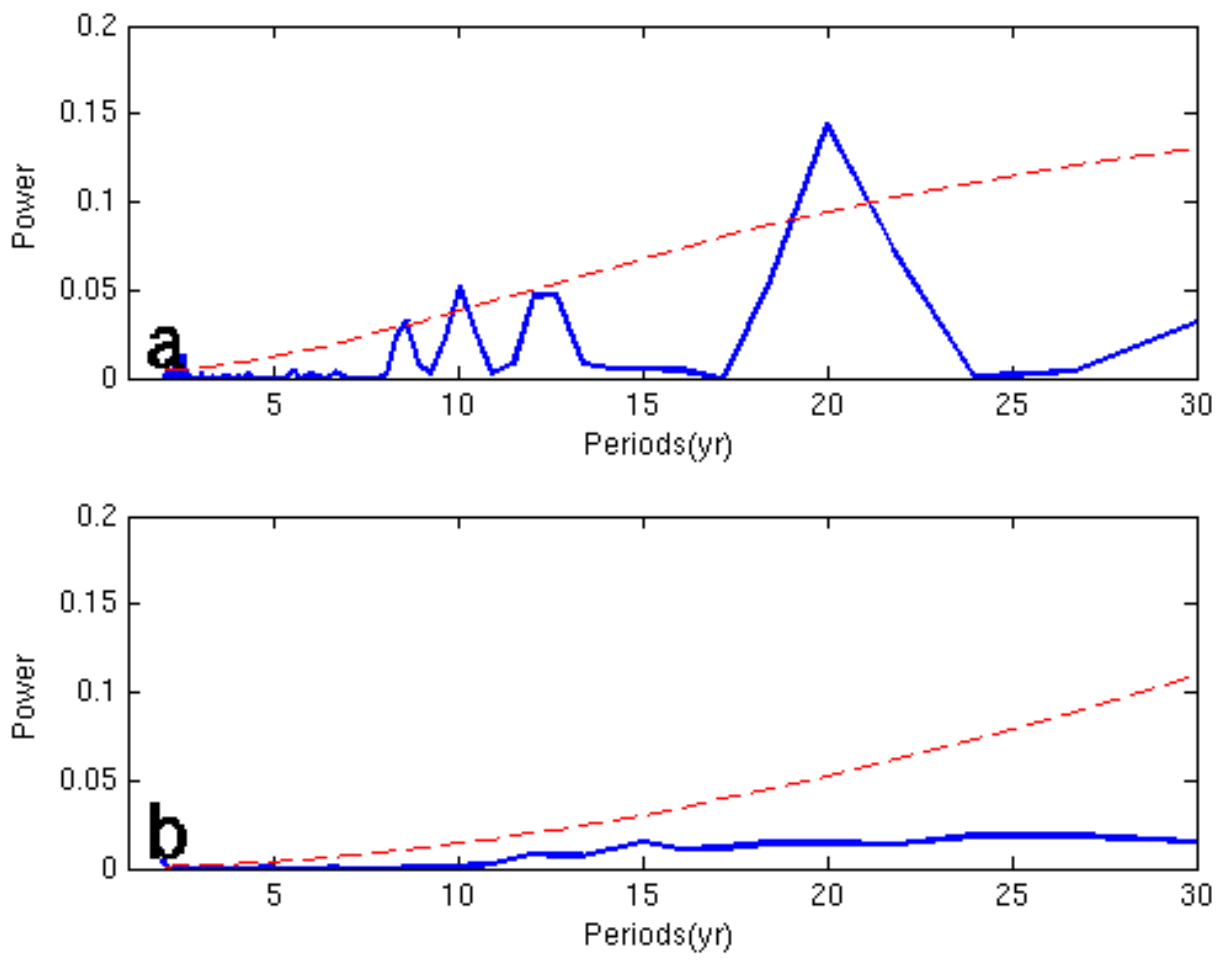

Figure 15. Power spectra of DWBC transport (blue line) in the (a) control run and (b) water-hosing run. The red dashed line represents the $95 \%$ confidence level. 